Voraussetzung für die Arbeit in einer Europäischen Institution sind gute Englischkenntnisse. Wegen des internationalen Arbeitsumfeldes wird grundsätzlich immer Englisch gesprochen und auch E-Mails werden auf Englisch verfasst. Eine zusätzliche Ausbildung in fachspezifischem Englisch braucht man jedoch meiner Meinung nach ebenso wenig wie einen Lebenslauf mit Stationen im englischsprachigen Ausland. Durch den täglichen Umgang mit fachspezifischen Termini werden die relevanten Begriffe schnell geläufig. Für den Alltag sind Französischkenntnisse hilfreich, da in Brüssel Französisch Amtssprache ist (neben Niederländisch) und man sich deshalb besser zurechtfindet.

Fachlich ist es meiner Meinung nach notwendig, dass man Grundkenntnisse im EU-Recht hat (die Institutionen, die Rechtsgrundlagen und die unterschiedlichen Handlungsformen). Wichtiger als ein detailliertes Europarechtswissen ist jedoch die Fähigkeit, sich schnell in neue Rechtsgebiete hineindenken zu können und auch mit ungewohnten Fragestellungen umgehen zu können. Beispielsweise musste ich bei einer parlamentarischen Anfrage eine bestimmte Richtlinie auslegen oder EuGH-Urteile zusammenfassen. Durch die noch frische Ausbildung im Referendariat ist dies aber meist ohne größere Schwierigkeiten möglich. Gerade deshalb werden die „legal trainees“ auch geschätzt.

Trotz der Tatsache, dass mein Aufenthalt in Brüssel nur wenige Monate dauerte, habe ich diesen Abschnitt meiner Ausbildung als einen der informativsten, intensivsten und motivierendsten erlebt. Gerade deshalb würde ich mir wünschen, dass noch viele junge Juristinnen über ihren Schatten springen und bereits am Anfang ihrer Karriere die einmalige Chance nutzen, einen Einblick in die Schaltzentralen europäischer Politik zu erhalten.

\title{
Vermittlung von Auslandsstationen in EU-Institutionen
}

Djb-Mitglieder können sich um die Vermittlung einer Auslandsstation in EU-Institutionen während des Referendariats bewerben. Bitte senden Sie dazu Ihre Bewerbungsunterlagen (Motivationsschreiben, gewünschter Zeitpunkt, Stelle sowie tabellarischer Lebenslauf) an die Beisitzerinnen, welche diese direkt an potentielle Arbeitgeberinnen/Vermittlerinnen und
Arbeitgeber/Vermittler in EU-Institutionen (insbesondere EU-Kommission und EU-Parlament) weiterleiten.

\section{Kontakt:}

beisitzerinnen@djb.de

Weitere Informationen unter www.djb.de/JungeJuristinnen/EU. 